\section{Peptidylprolyl Isomerase A (PPIA) as a Preferred Internal Control Over GAPDH and $\beta$-Actin in Quantitative RNA Analyses}

BioTechniques 32:776-782 (April 2002)

\begin{abstract}
A good internal control is critical in all quantitative analyses of gene expression. Levels of $\beta$-actin, glyceraldehyde-3-phosphate dehydrogenase (GAPDH), and peptidylprolyl isomerase A (PPIA) were analyzed in 78 samples (data obtained from our laboratory and from a publicly available database at http://www.ncbi.nlm.nih.gov/ SAGE/). These libraries included cell lines and tissues from brain, breast, colon, kidney, ovary, pancreas, prostate, skin, and vascular origin. The level of PPIA mRNA is the most constant among the three genes. Hence, our study suggests that PPIA is a better internal control than $\beta$-actin or GAPDH, the two most commonly used internal controls.
\end{abstract}

\section{INTRODUCTION}

Quantitative gene expression assays have been widely used to investigate many cellular and pathological events. Assessment of mRNA is typically referenced to an internal control gene such as glyceraldehyde-3-phosphate dehydrogenase (GAPDH) and $\beta$-actin. However, it has been shown that both GAPDH and $\beta$-actin are regulated by internal factors, such as the cell cycle (9), and by external factors, such as growth factors $(3,15)$, cytokines $(16)$, serum $(8,17)$, stress $(5,23$, $25)$, vitamins $(2,12)$, and other chemical compounds such as dioxins (10) and neuroendocrine peptide (26). In addition, GAPDH has proven to be an inappropriate internal standard for studies involving comparisons between certain tissues and corresponding cell lines (13) or between normal and tumor samples $(1,4,7)$. Thus, the choice of an internal standard with consistent expression levels under all experimental conditions is crucial for accurate quantitative data analysis.
We have performed serial analysis of gene expression (SAGE) on human prostate samples (22) to identify genes that are regulated by dihydrotestosterone (DHT) and to find genes that are differentially expressed between normal prostate and tumor tissues. We identified approximately 800 genes that were differentially expressed, including GAPDH and $\beta$-actin. In search of an alternative internal control, we identified the peptidylprolyl isomerase A (PPIA) gene (also known as cyclophilin A). Here we provide evidence that shows PPIA as a better internal control than $\beta$ actin and GAPDH.

\section{MATERIALS AND METHODS}

\section{Samples}

Prostate cell lines LNCaP, PC3, and DU145 and tissues were obtained, maintained, and treated as described previously $(21,22)$.

\section{SAGE Data Analysis}

SAGE data for human prostate were generated and analyzed as described previously $(20,22)$. SAGE data for other tissue types were obtained from the National Center for Biotechnology Institute (NCBI) SAGE databank (http://
www.ncbi.nlm.nih.gov/SAGE/). Only libraries larger than 10000 transcripts were included in our analysis.

\section{External Control RNA}

pLacZ(A)28 contains a fragment of the lac $Z$ gene (2181 bp) and a poly(A) tail ( 28 bases) under the control of the T7 promoter. pLacZ(A)28 was linearized by restriction digestion with NotI and then purified using Wizard ${ }^{\circledR}$ (Promega, Madison, WI, USA). Transcription in vitro was performed with the Megascript ${ }^{\mathrm{TM}}$ High-Yield Transcription kit (Ambion, Austin, TX, USA) using $1 \mu \mathrm{g}$ linearized plasmid DNA. Template DNA was removed by treatment with $2 \mathrm{U}$ DNase $\mathrm{I}$ at $37^{\circ} \mathrm{C}$ for $15 \mathrm{~min}$, and RNA was purified using TRIzOL ${ }^{\circledR}$.

\section{Reverse Transcription}

cDNA was reverse-transcribed from $1 \mu \mathrm{g}$ total RNA from each prostate sample in the presence of $5 \times 10^{6} \mathrm{~mol}-$ ecules of LacZ transcribed in vitro with the SUPERSCRIPT ${ }^{\mathrm{TM}}$ II reverse transcriptase, as recommended by the manufacturer (Invitrogen, Carlsbad, CA, USA).

\section{Quantitative PCR}

Real-time quantitative PCR was performed on an iCycler ${ }^{\mathrm{TM}}$ (Bio-Rad Lab-

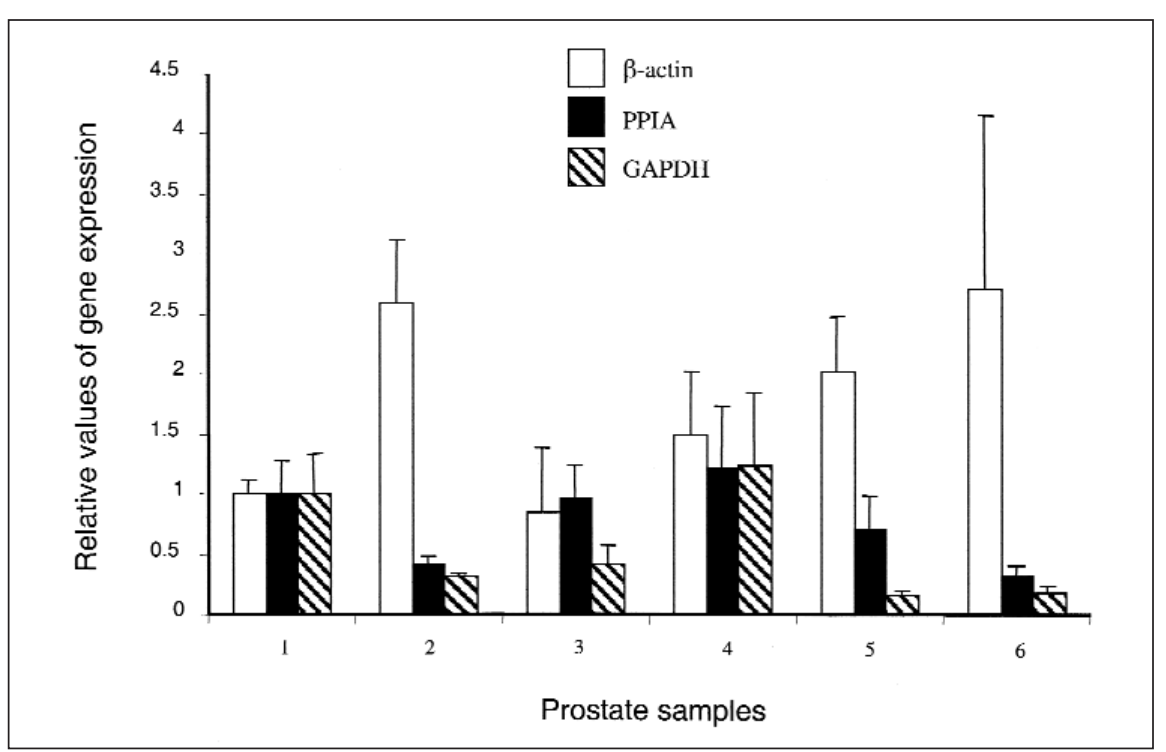

Figure 1. Comparison of the expression pattern of GAPDH, PPIA and $\beta$-actin in prostate samples, as determined by quantitative PCR. 1, PC3; 2, DU145; 3, LNCaP; 4, LNCaP+DHT; 5, tumor tissues; and 6, normal tissues. PC3 was designated as the calibrator and given a value of 1. 
oratories, Hercules, CA, USA). All primers were designed using the Oligo Express $^{\mathrm{TM}}$ program (Molecular Biology Insights, Cascade, CO, USA) as previously described (21). Primers used were: lacZ control forward $5^{\prime}$-GCTTTCGCTACCTGGAGAGAC- $3^{\prime}$ and reverse 5'-GAAACGCCGCCAGTATTTAG-3'; PPIA forward 5'-CAAATGCTGGACCCAACACA- $3^{\prime}$ and reverse 5'-TGCCATCCAACCACTCAGTC-3'; GAPDH forward 5'-GAAGGTGAAGGTCGGAGTC- $3^{\prime}$ and reverse $5^{\prime}$-GAAGATGGTGATGGGATTC-3'; and $\beta$-actin forward $5^{\prime}$-TGAGGCCCAGAGCAAGAGA-3' and reverse $5^{\prime}$-TCGTCCCAGTTGGTGACGAT- $3^{\prime}$.

To determine the relative quantity of PPIA in each sample, the amount of PPIA was normalized to that of lacZ. The normalized amount of PPIA is a unitless number that was used to compare the relative amount in different samples. To make this comparison, PC3 was designated as the calibrator (given the value of 1). The relative values were obtained by dividing the normalized value of a sample with that of PC3. The standard deviation of the quotient was calculated from the standard deviation of PPIA and lacZ values using the following formula for the coefficients of variation:

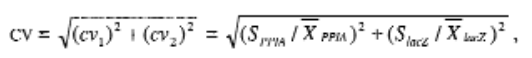

[Eq. 1] where $\mathrm{CV}=\mathrm{S} / \bar{X}, \mathrm{~S}$ is the standard deviation and $\bar{X}$ is the mean value. Therefore, the standard deviation of a quotient $=(\mathrm{CV})(\bar{X})$. Relative amounts of GAPDH and $\beta$-actin were calculated using the same formulae.

\section{Statistical Analysis}

Expression data for each of the three candidate genes were recorded as one observation per sample per organ. We assume that the distribution of expression is the same for each gene in all tissue types for a given organ. First, each gene was analyzed separately. A oneway analysis of variance (ANOVA) was used to test differences in the mean gene expression among the organs (11). Levene's test was used to test the homogeneity of variances across organs. When variances were found to differ across organs, Welch's varianceweighted ANOVA (24) was used. The Kruskal-Wallis test (6) was used to corroborate the results of parametric tests. Whenever the null hypothesis of equality of means across all organs was rejected, plots of organ-specific means were examined to identify subgroups of organs for which the mean levels were similar. We then tested the equality of mean expressions in the subgroups. One-sided Pitman tests (14) for equality of variance for paired data were used to assess the variability of expression

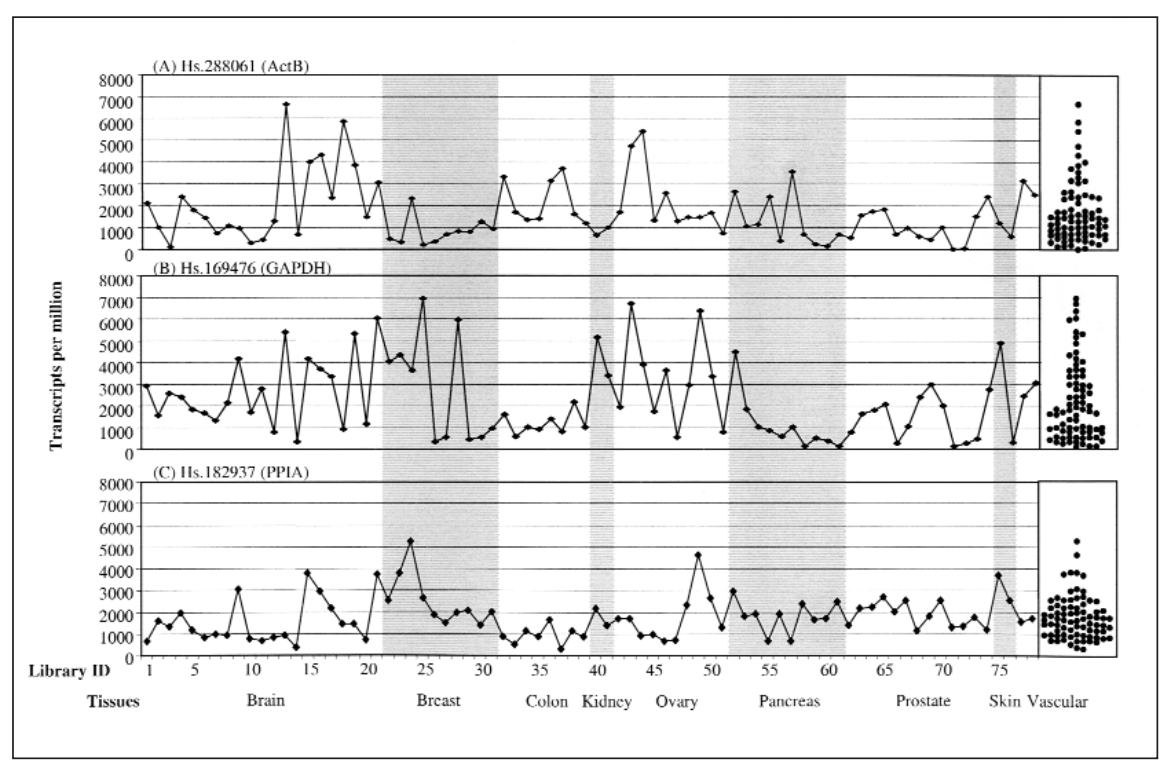

Figure 2. Comparison of expression pattern of $\beta$-actin (A), GAPDH (B), and PPIA (C) in different tissue types. The column on the right demonstrates the distribution of the transcripts. 


\section{Short Technical Reports}

Table 1. Means and Standard Errors of Gene Expressions by Organ

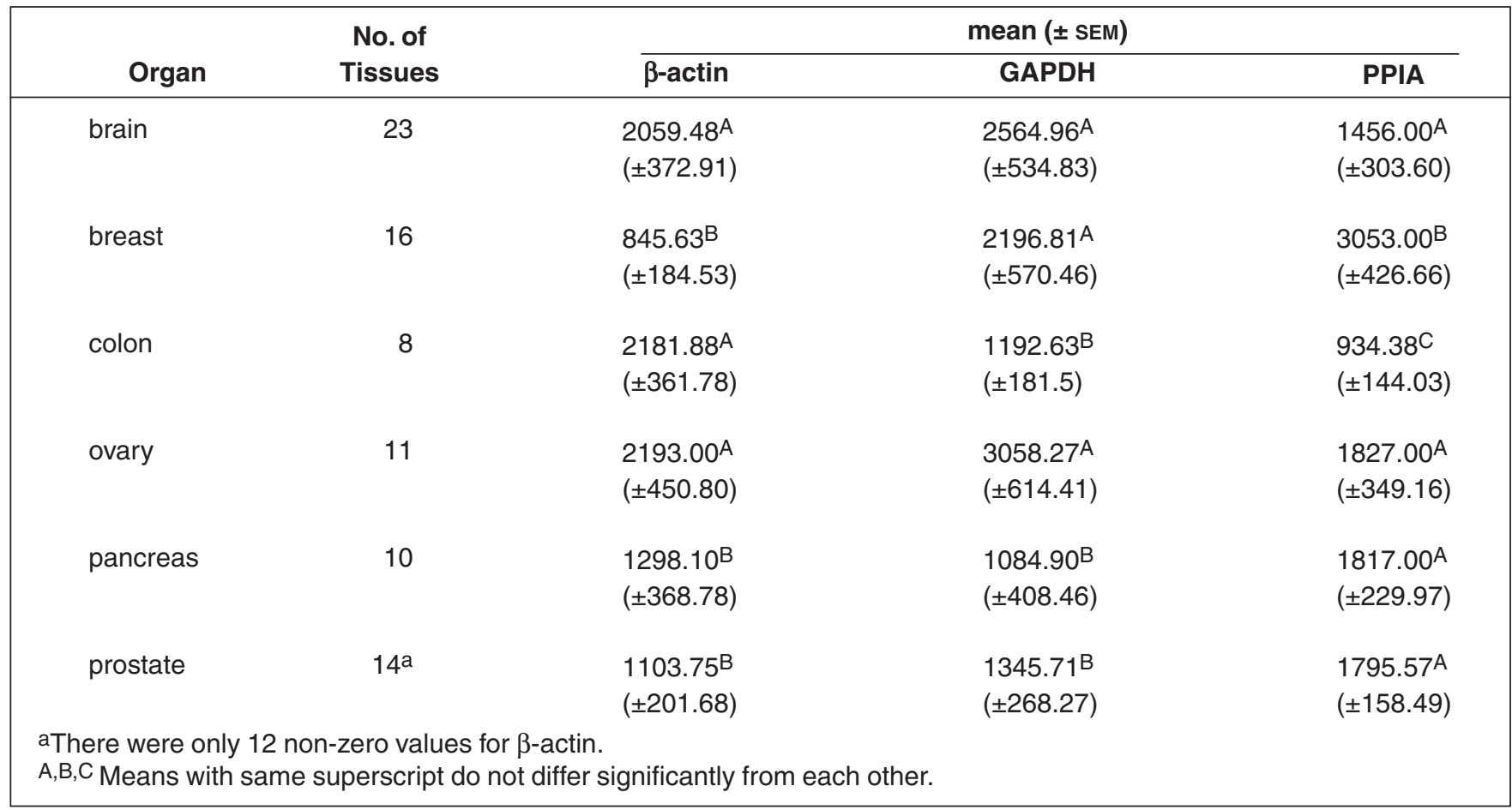

Table 2. $P$ Values for One-Sided Pitman Tests of Homogeneity of Gene Expression Variance Between PPIA and Competitors by Organ

\begin{tabular}{|c|c|c|c|c|c|c|}
\hline \multirow[b]{2}{*}{ Organ } & \multirow{2}{*}{$\begin{array}{c}\text { No. of } \\
\text { tissues }\end{array}$} & \multicolumn{3}{|c|}{ SD } & \multirow{2}{*}{$\begin{array}{c}\text { PPIA vs. } \\
\beta \text {-actin }\end{array}$} & \multirow{2}{*}{$\begin{array}{l}\text { PPIA vs. } \\
\text { GAPDH }\end{array}$} \\
\hline & & $\beta$-actin & GAPDH & PPIA & & \\
\hline brain & 23 & 1788.39 & 1587.51 & 1025.29 & 0.004 & 0.007 \\
\hline breast & 16 & 738.13 & 2281.84 & 1706.65 & $0.001^{b}$ & 0.13 \\
\hline colon & 8 & 1023.26 & 513.36 & 407.37 & 0.02 & 0.26 \\
\hline ovary & 11 & 1495.12 & 2037.77 & 1158.04 & 0.22 & 0.03 \\
\hline pancreas & 10 & 1166.19 & 1291.65 & 727.24 & 0.09 & 0.05 \\
\hline prostate & $14^{a}$ & 698.64 & 1003.77 & 593.02 & 0.22 & 0.04 \\
\hline
\end{tabular}

across organs. This analysis was performed separately for each organ because the visual inspection of the plot of expression data for each candidate gene indicated that organ-specific expression variances vary greatly from one organ to another (confirmed by Levene's test).

\section{RESULTS AND DISCUSSION}

An ideal gene serving as an internal control would be one whose expression remains constant under any conditions in all tissue types. However, it is unlikely that such a gene would exist since biological systems are dynamic and constantly responding to their environme nt. Therefore, the most appropriate internal control would be one that has the least variation in its expression under various experimental conditions and in different tissue types. With our previous SAGE data, we performed a thorough search for genes that were expressed at a similar level in the absence or presence of androgen and in normal or tumor tissue. We identified 77 genes that were not differentially expressed $(P>0.5)$. Among those genes, we selected those that were expressed at a level similar to that of $\beta$-actin and GAPDH. With these criteria, we identified the gene PPIA.

To confirm the steady level of PPIA expression, we performed quantitative PCR analysis and compared the variability in the expression of PPIA to that of $\beta$-actin and GAPDH in prostate sam- 


\section{Short Technical Reports}

ples PC3, DU145, LNCaP (with and without DHT treatment), and tumor and normal tissues. A slight difference in expression patterns was observed for GAPDH, $\beta$-actin, and PPIA in LNCaP cells treated with or without DHT (Figure 1). Although these differences may not be statistically significant, PPIA appeared to show the least variability. This suggested that PPIA is a better internal control under these conditions than GAPDH or $\beta$-actin. In tumor versus normal tissues, GAPDH appeared to be more constant than PPIA.

To determine the expression pattern of these three genes in other tissue types and experimental conditions, we analyzed 78 SAGE libraries. Figure 2 shows a comparison of the expression distribution of PPIA to that of GAPDH and $\beta$-actin. Since only two observations of expression were available for skin, vascular, and renal tissue, we restricted our analysis to brain, breast, colon, ovary, pancreas, and prostate. Welch's ANOVA procedure was used for all models since organ-specific expression variances were found to be significantly inhomogeneous for PPIA $(P=0.03)$ and GAPDH $(P=0.008)$ and marginally so for $\beta$-actin $(P=0.09)$.

The mean expression of PPIA among brain, ovary, pancreas, and prostate tissues was similar $(P=0.23)$ (Table 1$)$. Interestingly, the mean expression was much higher $(P=0.004)$ in breast tissue and much lower $(P=0.03)$ in colon tissue than the other four organs. These results were corroborated by nonparametric tests. In the case of $\beta$-actin, its mean expressions appeared to be closer in tissues of the brain, colon, and ovary. The mean expressions in prostate and pancreas tissues were similar but approximately $50 \%$ less than that of brain, colon, and ovary. The mean expression in the breast was the lowest. Significant differences in GAPDH expression were detected when the means for all six organs were compared $(P=0.005)$. In comparison with $\beta$-actin, PPIA had significantly lower variability of expression levels in brain and colon tissues (Table 2). Although the difference was not statistically significant, PPIA variance was lower in ovarian, pancreatic, and prostate tissue. Note that the variance of PPIA was significantly higher than that of $\beta$-actin in breast tissue $(P=0.001)$. The variability of PPIA expression was significantly lower than GAPDH in brain, ovarian, and prostate tissue. In fact, the PPIA expression variance was lower than that of GAPDH for all six organs (Table 2). These results indicated that PPIA expression is more consistent than that of $\beta$-actin and GAPDH in a majority of organs analyzed.

The use of the PPIA gene as an internal control has been cited in a few papers (21). Other molecules such as $18 \mathrm{~S}$ rRNA, 28S rRNA, 36B4, HPRT, and 
tubulin have also been used as controls $(18,19)$. However, rRNA molecules are unsuitable as internal standards for any analysis in which mRNA is the source reagent. HPRT, on the other hand, has been excluded from our study, as the gene is not highly expressed in many SAGE libraries derived from cell lines and tissues. In addition, like HPRT, tubulin is not widely used as an internal control. To date, no systematic study of the expression of these housekeeping genes has been reported. To our knowledge, this report is the first comprehensive study that compares the expression levels of GAPDH, $\beta$-actin, and PPIA in a large sample setting. The results of our study suggest that PPIA is a better internal control than GAPDH or $\beta$-actin in most circumstances. We recommend the use of PPIA as an internal control in RNA quantitative studies.

\section{REFERENCES}

1.Bhatia, P., W.R. Taylor, A.H. Greenberg, and J.A. Wright. 1994. Comparison of glyceraldehyde-3-phosphate dehydrogenase and 28S ribosomal RNA gene expression as RNA loading controls for northern blot analysis of cell lines of varying malignant potential. Anal. Biochem. 216:223-226.

2.Desprez, P.Y., D. Poujol, and S. Saez. 1992. Glyceraldehyde-3-phosphate dehydrogenase (GAPDH, E.C. 1.2.1.12.) gene expression in two malignant human mammary epithelial cell lines: BT20 and MCF-7. Regulation of gene expression by 1,25-hydroxyvitamin D3 (1,25-(OH)2D3). Cancer Lett. 64:2219-2224.

3.Einat, M., D. Resnitzky, and A. Kimchi. 1985. Inhibitory effects of interferon on the expression of genes regulated by platelet-derived growth factor. Proc. Natl. Acad. Sci. USA 82:7608-7612.

4.Epner, D.E., A.W. Partin, J.A. Schalken, J.T. Isaacs, and D.S. Coffey. 1993. Association of glyceraldehyde-3-phosphate dehydrogenase expression with cell motility and metastatic potential of rat prostatic adenocarcinoma. Cancer Res. 53:1995-1997.

5.Garmyn, M., M. Yaar, N. Holbrook, and B.A. Gilcrest. 1994. Immediate and delayed molecular response of human keratinocytes to solar-simulated irradiation. Lab. Invest. 65:471-478.

6.Hollander, M. and D.A. Wolfe. 1973. Nonparametric statistical methods. John Wiley and Sons, New York.

7.Lau, W.Y., P.B. Lai, M.F. Leung, N. Wong, G. Chen, T.W. Leung, and C.T. Liew. 2000. Differential gene expression of hepatocellular carcinoma using cDNA microarray analyses. Oncol. Res. 12:59-69.

8.Lowe, W.L., Jr., M. Kummer, C.W. Karper, and X.D. Wu. 1990. Regulation of insulinlike growth factor 1 messenger ribonuclease acid levels by serum in cultured rat fibroblasts. Endocrinology 127:2854-2861.

9.Mansur, N.R., K. Meyer-Seigler, J.C. Wurzer, and M.A. Sirover. 1993. Cell cycle regulation of the glyceraldehyde-3-phosphate dehydrogenase/uracil DNA glycosylase gene in normal human cells. Nucleic Acid Res. 21:993-998.

10.McNulty, S.E. and W.A. Toscano, Jr. 1995. Transcriptional regulation of glyceraldehyde3-phosphate dehydrogenase by 2,3,7,8-tetrachlorodibenzo-p-dioxin. Biochem. Biophys. Res. Comm. 212:165-171.

11.Neter, J., M.H. Kutner, C.J. Nachtsheim, and W. Wasserman. 1996. Applied linear statistical models. Richard D. Irwin, Chicago.

12.Oka, T., N. Komori, M. Kuwahata, T. Sassa, I. Suzuki, M. Okada, and Y. Natori. 1993. Vitamin B6 deficiency causes activation of RNA polymerase and general enhancement of gene expression in rat liver. FEBS Lett. 331:162-164.

13.Oliveira, J.G., R.Z. Prados, A.C.M. Guedes, P.C.P. Ferreira, and E.G. Kroon. 1999. The housekeeping gene glyceraldehyde-3-phosphate dehydrogenase is inappropriate as internal control in comparative studies between skin tissue and cultured skin fibroblasts using northern blot analysis. Arch. Dermatol. Res. 291:659-661.

14.Pittman, E.J.G. 1939. A note on normal correlation. Biometrika 31:9-12.

15.Ranganna, K. and F.M. Yatsu. 1997. Inhibition of platelet-derived growth factor BB-induced expression of glyceraldehyde-3-phosphate dehydrogenase by sodium butyrate in rat vascular smooth muscle cells. Throm. Vasc. Biol. 17:3420-3427.

16.Sabath, D.E., H.E. Broome, and M.B. Prystowsky. 1990. Glyceraldehyde-3-phosphate dehydrogenase mRNA is a major interleukin 2-induced transcript in a cloned T-helper lymphocyte. Gene 91:185-191.

17.Schmittgen, T.D. and B.A. Zakrajsek. 2000. Effect of experimental treatment on housekeeping gene expression: validation by realtime, quantitative RT-PCR. J. Biochem. Biophys. Methods 46:69-81.

18.Spanakis, E. 1993. Problems related to the interpretation of autoradiographic data on gene expression using common constitutive transcripts as controls. Nucleic Acids Res. 21:3809-3819.

19.Suzuki, T., P.J. Higgins, and D.R. Crawford. 2000. Control selection of RNA quantitation. BioTechniques 29:332-337.

20.Velculescu, V.E., L. Zhang, B. Vogelstein, and K.W. Kinzler. 1995. Serial analysis of gene expression. Science 270:484-487.

21.Waghray, A., F. Feroze, M. Schober, F. Yao, C. Woods, E. Puravs, M. Krause, S. Hanash et al. Identification of androgen-regulated genes in the prostate cancer cell line $\mathrm{LNCaP}$ by serial analysis of gene expression and proteomic analysis. Proteomics (In Press).

22.Waghray, A., M. Schober, F. Feroze, F. Yao, J. Virgin, and Y.Q. Chen. 2001. Identification of differentially expressed genes by serial analysis of gene expression in human prostate cancer. Cancer Res. 61:4283-4286.

23.Weill, D., F. Gay, M.G. Tovey, and S. Chouaib. 1996. Induction of tumor necrosis factor $\alpha$ expression in human T lymphocytes following ionizing $\gamma$ irradiation. J. Interferon Cytokine Res. 5:395-402.

24.Welch, B.L. 1938. The significance of the difference between two means when the population variances are unequal. Biometrika 29:350-362.

25.Woloschak, G.E., C.M. Chang-Liu, P.S. Jones, and C.A. Jones. 1990. Modulation of gene expression in Syrian hamster embryo cells following ionizing radiation. Cancer Res. 50:339-344.

26.Yuan, S., L. Rosenberg, A. Illieva, D. Agapitos, and W.P. Duguid. 1999. Early changes of gene expression during cerulein supramaximal stimulation. Pancreas 19:4550.

27.Zhong, H. and J.W. Simons. 1999. Direct comparison of GAPDH, $\beta$-actin, cyclophilin, and 28s rRNA as internal standards for quantifying RNA levels under hypoxia. Biochem. Biophys. Res. Commun. 259:523-526.

Address correspondence to Dr. Y.Q. Chen, Department of Cancer Biology, Wake Forest University, Medical Center Blvd., Winston-Salem, NC 27157, USA. e-mail: yqchen@wfubmc.edu

Received 13 June 2001; accepted 10 December 2001.

\section{F. Feroze-Merzoug, I.M. Berquin ${ }^{1}$, J. Dey, and Y.Q. Chen}

Wayne State University

Detroit

${ }^{1}$ University of Michigan

Ann Arbor, MI, USA

For reprints of this or
any other article, contact
Reprints@BioTechniques.com

